\title{
The UNC-14 protein required for axonal elongation and guidance in Caenorhabditis elegans interacts with the serine/threonine kinase UNC-51
}

\author{
Ken-ichi Ogura, ${ }^{1,3}$ Megumi Shirakawa, ${ }^{1}$ Thomas M. Barnes, ${ }^{2}$ Siegfried Hekimi, ${ }^{2}$ and \\ Yasumi Ohshima ${ }^{1,4}$ \\ ${ }^{1}$ Department of Biology, Faculty of Science, Kyushu University, Fukuoka 812-81, Japan; ${ }^{2}$ Department of Biology, McGill \\ University, Montreal H3A 1B1, PQ Canada
}

\begin{abstract}
Certain unc mutants in the nematode Caenorhabditis elegans, such as unc-14 and unc-51, show abnormal axonal elongation and axonal structures. We cloned the unc-51 gene previously and predicted that it encodes a novel serine/threonine protein kinase. In this study, we precisely localized the activity to rescue an unc-14 mutation. Also, we identified four cDNA clones encoded by the unc-14 rescuing region, in screens for proteins that bind to UNC-51 using a yeast two-hybrid system. A mutation site in the cDNA was identified for each of the six unc-14 mutants, establishing that the unc-14 gene was cloned. The unc-14 gene encodes a novel protein of 665 amino acids, and is coexpressed with the unc-51 gene in the cell bodies and axons of almost all neurons including DD/VD and hermaphrodite-specific neurons. Another clone recovered in the two-hybrid screen encodes a carboxy-terminal region of UNC-51. Analysis using the yeast two-hybrid system suggested that a central region of UNC-14 bound to a carboxy-terminal region of UNC-51, and that the UNC-51 carboxy-terminal region oligomerized. In in vitro binding studies using recombinant fusion proteins, UNC-14 interacted with UNC-51 directly. We propose that UNC-51 protein kinase acts as an oligomer, and that UNC-14 is a regulator of UNC-51, in axonal elongation and guidance.
\end{abstract}

[Key Words: C. elegans; unc-14; unc-51; axonal elongation; axonal guidance; serine/threonine kinase]

Received March 10, 1997; revised version accepted May 27, 1997.

In the nematode Caenorhabditis elegans, $>10$ genes generally required for normal axonal guidance or elongation have been identified mutationally and analyzed in detail (Brenner 1974; Hedgecock et al. 1987; Desai et al. 1988; Siddiqui 1990; McIntire et al. 1992).

unc-5, unc- 6 , and unc- 40 genes are required for guiding circumferential elongation of pioneer axons and migration of mesodermal cells on the epidermis (Desai et al. 1988; Hedgecock et al. 1990; Siddiqui 1990; McIntire et al. 1992). The unc-6 gene, required for both dorsal and ventral elongation and migration, encodes a $C$. elegans ortholog of vertebrate netrins, which is expressed in neuroglia and neurons along the ventral midline (Ishii et al. 1992; Wadsworth et al. 1996). Netrin-1 and netrin-2 have been identified as chemoattractants for developing axons (Serafini et al. 1994). Netrin-1 also functions as a chemorepellent (Colamarino and Tessier-Lavigne 1995). The function and expression patterns of Unc- 6 and net-

${ }^{3}$ Present address: Gene Network Laboratory, National Institute of Genetics, Mishima, Shizuoka 411, Japan.

${ }^{4}$ Corresponding author.

E-MAIL yohshscb@mbox.nc.kyushu-u.ac.jp; FAX 81-92-642-2645. rins are conserved phylogenetically from the nematode to vertebrates. The unc-5 gene is required for dorsal elongation and encodes a transmembrane protein with immunoglobulin and thrombospondin type 1 domains (Leung-Hagesteijn et al. 1992). Mosaic analysis showed that the unc- 5 gene acts in migrating cells and pioneering neurons. The unc- 40 gene required for ventral elongation and partly for dorsal elongation encodes a nematode homolog of the vertebrate cell adhesion molecule DCC (deleted in colorectal cancer), and is expressed in motile cells and pioneering neurons (Chan et al. 1996). DCC is expressed in the nervous system in developing embryos (Chuong et al. 1994; Pierceall et al. 1994). It was revealed recently that DCC is a netrin receptor (KeinoMasu et al. 1996), suggesting that Unc-40 is a component of Unc- 6 receptors (Chan et al. 1996).

Mutations in the genes unc-34, unc-71, and unc-76 disrupt longitudinal elongation of axons along the nerve cords and their fasciculation. Therefore, these genes may encode components important for the interaction between axons or between growth cones and axons (McIntire et al. 1992; Bargmann 1993).

The genes unc-14, unc-33, unc-44, unc-51, and unc- 
73 are required for circumferential axonal growth over lateral hypodermis, longitudinal axonal elongation along the nerve cords, and axonal fasciculation. Mutations in these genes lead to various abnormalities in axonal structures as well as in axonal elongation or guidance (Hedgecock et al. 1985; Desai et al. 1988; Siddiqui 1990; McIntire et al. 1992), suggesting that these genes may be primarily involved in the formation of basic axonal structures (McIntire et al. 1992). The unc-33 gene encodes a novel protein (Li et al. 1992). Although the precise function of Unc-33 is still unknown, related proteins have been identified. A collapsin response mediator protein CRMP-62, required for collapsin-induced inward currents in Xenopus laevis oocytes, shares homology with Unc-33 (Goshima et al. 1995). The unc-44 gene encodes a putative ankyrin-related protein (Otsuka et al. 19951.

Mutations in unc-51 and unc-14 genes show quite similar phenotypes; namely, they cause various abnormalities in many neurons, although those of unc-14 mutations are weaker (Hedgecock et al. 1985; Desai et al. 1988; McIntire et al. 1992). For example, dorsal extensions along the lateral hypodermis of axons of the DD/ VD motor neurons are prematurely terminated or misdirected in $-50 \%$ in unc-51(e369) and in $-20 \%$ in unc14(e157) (McIntire et al. 1992). In our results, most of the $\mathrm{DD} / \mathrm{VD}$ axons in unc-51(e369) were terminated prematurely during ventral extensions (Ogura et al. 1994) and $-20 \%$ of them in unc-14(e57) (data not shown). The axons of hermaphrodite-specific neurons (HSN) that are extended anteriorly along the ventral nerve cord are also terminated frequently in unc-51 and unc-14 mutants (Desai et al. 1988; McIntire et al. 1992). Furthermore, in unc-14 and unc-51 mutants, processes of DD/VD, HSN, and other GABA-nergic or serotonergic neurons examined contain many large, atypical varicosities. Ultrastructural examination of unc-14 and unc-51 mutants revealed defects in membranous structures, including significant enlargements in axon diameter and many abnormal vesicles and cisternae-like structures within axons (McIntire et al. 1992). These structural abnormalities in axons are similar to those found in the temperature-sensitive shibire mutant of Drosophila (Koenig et al. 1983; Kosaka and Ikeda 1983), as pointed out by McIntire et al. (1992). The shibire mutant shows blockage of neurite development and growth cone formation in neuronal cultures at the restrictive temperature, and these defects were presumed to be related to defective membrane recycling and endocytosis (Kim and Wu 1987). Thus, it is possible that the unc-51 gene is involved in axonal membrane recycling (Ogura et al. 1994).

We cloned the unc-51 gene previously and showed that it encoded a predicted novel serine/threonine protein $\mathrm{ki}$ nase (Ogura et al. 1994). The kinase domain is essential for the function, because a point mutation in the predicted ATP binding region resulted in loss of rescuing activity. An unc-51::lac $Z$ fusion gene was expressed in almost all neurons at all stages, and this fusion product was localized to axons and cell bodies. These results suggest that UNC-51 acts in axons and regulates axonal elongation and fasciculation by phosphorylation. Because many phosphorylated proteins have been found in the nervous system, related kinases probably function in the nervous system of other organisms as well (Manser et al. 1994; Hill et al. 1995). To analyze the function of UNC-51 further, we searched for UNC-51 binding proteins using a yeast two-hybrid system (Fields and Song 1989; Chien et al. 1991). In this approach and by positional cloning, we identified the unc-14 gene and we show that UNC-51 can interact with UNC-14 directly.

\section{Results \\ Positional cloning of unc-14}

unc-14 had been mapped genetically between the genes sem-4 (Basson and Horvitz 1996) and myo-1 (Dibb et al. 1989), which probably corresponds to let-75 (cited in Starich et al. 1996). Using a pool of 11 overlapping cosmid clones that covered this region (Fig. 1A), we were able to rescue the locomotory defect of unc-14(e57). The rescuing pool was split into three overlapping subpools, only the middle one of which was able to rescue (Fig. 1A). This indicated that the rescuing region was centered on cosmid $\mathrm{R} 05 \mathrm{H} 7$. We generated a genomic restriction map encompassing $\mathrm{R} 05 \mathrm{H} 7$ and flanking regions, and determined the extents of several additional clones from the physical map that lay in this region. The activity of rescuing the unc-14 mutation was shown to lie in the 15-kb overlap between R12F2 and R01B1 (Fig. 1B). A series of subclones was tested for rescue (Fig. 1C), which showed that the $4.8-\mathrm{kb}$ region between the HindIII boundary of pRA18 and the XhoI boundary of pR9.2 was sufficient to rescue the unc-14 mutation.

Identification of proteins interacting with UNC-51 by using a yeast two-hybrid system

In an independent approach, we sought proteins interacting with UNC-51 using a modified yeast two-hybrid system (Durfee et al. 1993). About $5 \times 10^{5}$ clones of a $C$. elegans cDNA library were screened, and 16 positive clones were obtained and partially sequenced. One positive clone out of the 16 was an unc- 51 cDNA, but encoded only the carboxy-terminal region (Fig. 2A). Four other clones were overlapping with one another (Fig. 2B), and matched cDNA clones isolated by Y. Kohara (pers. comm.). The latter cDNA clones had been positioned by hybridization to three YAC clones, Y39A9, Y51D6, and Y53F1, around the unc-14 locus (Fig. 1A; Y. Kohara, pers. comm.). Because unc-14 mutants have defects quite similar to those of unc-51 mutants, as described in the Introduction, we considered that these cDNA clones could correspond to the unc-14 gene. To examine this possibility, we hybridized the cDNA clone to several cosmids and subclones in the unc-14 region. Cosmid $\mathrm{R} 05 \mathrm{H} 7$ and the three subclones indicated in Fig- 


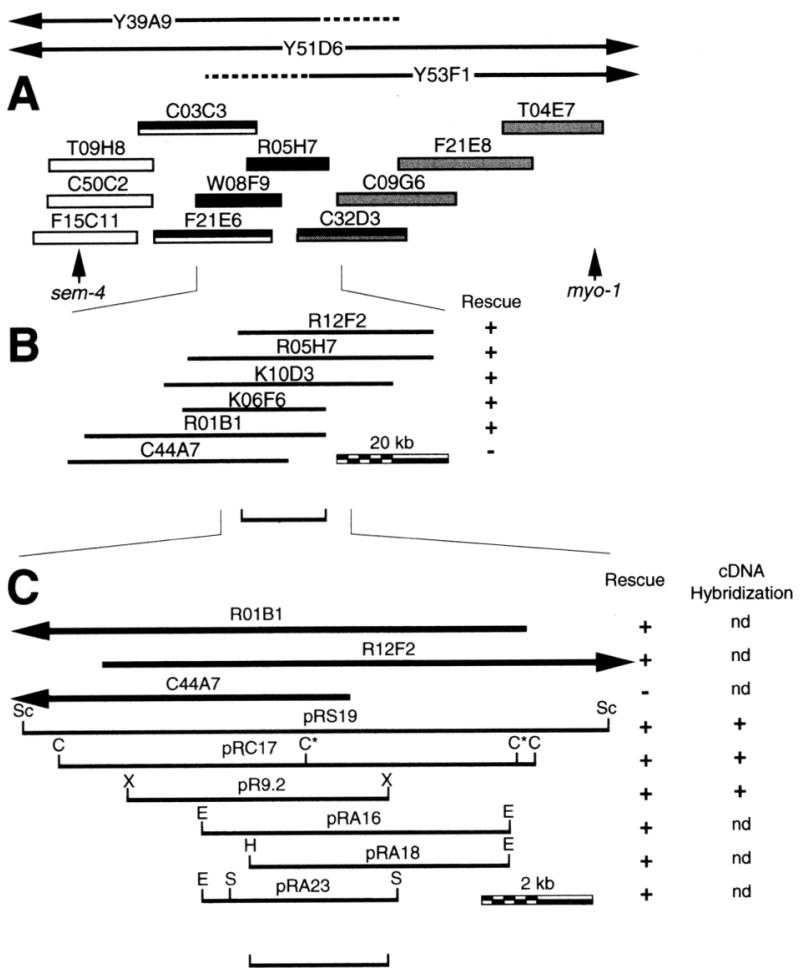

Figure 1. Localization of unc-14 rescuing activity. $(A)$ Selected clones from the physical map of the region are shown. The upper three lines correspond to YAC clones hybridizing to the unc-14 cDNA, whose precise endpoints are not known. The three subpools tested are indicated by different shadings. Note that $\mathrm{C} 03 \mathrm{C} 3, \mathrm{~F} 21 \mathrm{E} 6$, and C32D3 were common to two different subpools. $(B)$ Restriction mapping and rescue data for whole cosmids centered on the unc-14 region. Note that K06F6 was a corrupted clone, but contained the indicated region contiguously. The bracket at the bottom indicates the unc-14 rescuing region. (C) Rescue and hybridization data with subclones. Clones reacting with the cDNA probe are indicated. The bracket at the bottom indicates the unc-14 rescuing region. (Sc) SacII; (C) ClaI; (X) XhoI; (E) EcoRI; (H) HindIII; (S) SalI. Note that the large ClaI fragment contains two internal ClaI sites $\left(\mathrm{C}^{\star}\right)$ that were probably protected by overlapping dam methylation.

ure $\mathrm{IC}$ were positive, showing that the $\mathrm{CDNA}$ and the unc-14 rescuing region were coincident (Fig. 1C).

The longest cDNA clone was sequenced completely. Also, PCR analysis with both trans-spliced leaders SL1 and SL2 (Huang and Hirsh 1989) showed that the mRNA begins with SLl. The size of the mRNA deduced from the cDNA is $\sim 2.8 \mathrm{~kb}$. Northern hybridization of poly $(\mathrm{A})^{+}$ RNA from a population of mixed stages with a cDNA probe showed a band corresponding to this size, besides $3.5-$ and 1.8 -kb bands probably resulting from cross-hybridization with rRNAs (data not shown). The mRNA is predicted to encode a protein of 665 amino acid residues (Fig. 3). BLAST analysis of the entire sequence of this predicted protein revealed no remarkable homology $130 \%$ or more identify for a region of 100 amino acids or more, or a significant homology with a family of pro- teins) with the proteins predicted from the DDBJ nucleic acid sequence database. Surprisingly, the rescue data indicated that the carboxy-terminal region of UNC-14 was not required for rescue of locomotion: A fragment extending only down to the HindIII site (amino acids $1-370$, corresponding to $56 \%$ of UNC-14) readily rescued unc-14(e57). On the other hand, C44A7, which lacks the unc-14 promoter, $5^{\prime}$ untranslated region (UTR), and first few codons, did not rescue unc-14(e57). Genomic sequence analysis revealed that the unc-14 gene has 10 exons (Fig. 4). cDNAs from the six known unc-14 mutants were sequenced completely, and all had nonsense mutations near the amino terminus of the protein (Figs. 3 and 4; Table 1). These results establish that this novel protein is the unc-14 gene product.

Genetic interaction between unc-51 and unc-14 genes was examined by introduction of an unc-14 rescuing clone K06F6 or pR9.2 into unc-51(e369) mutant, which was not rescued. Introduction of an unc-51 rescuing clone ( $\mathrm{pF14}$ ) into unc-14(e57) was not successful. This result was possibly attributable to toxic overexpression of the unc-51 gene, because rescue of the unc-51 mutation with the unc-51 clone was also difficult.

\section{Expression patterns of unc-14 and unc-51 genes}

To analyze the expression pattern of unc-14, we constructed an unc-14::1ac $Z$ fusion gene that was capable of rescuing unc-14(e57). This fusion gene was expressed in almost all neurons in all stages, especially in cell bodies and axons (Fig. 5). As the expression pattern is very similar to that of an unc-51::1ac $Z$ fusion gene (Ogura et al. 1994), UNC-14 and UNC-51 appear to be coexpressed in most neurons.

To examine coexpression of unc-14 and unc-51 genes in DD/VD and HSN neurons that show axonal defects

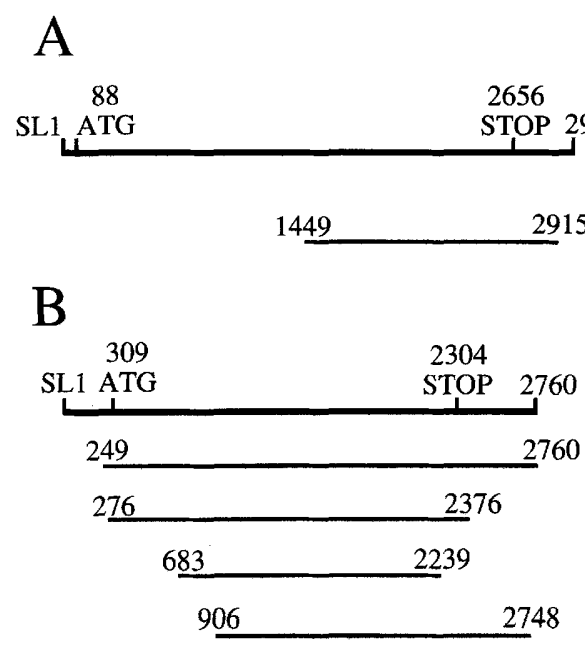

Figure 2. The cDNA clones isolated by the two-hybrid screening. The numbers represent the positions of the $5^{\prime}$ or $3^{\prime}$ ends of the cDNAs in comparison with the full-length cDNA. (A) An unc-51 cDNA clone; $(B)$ unc-14 cDNA clones. 


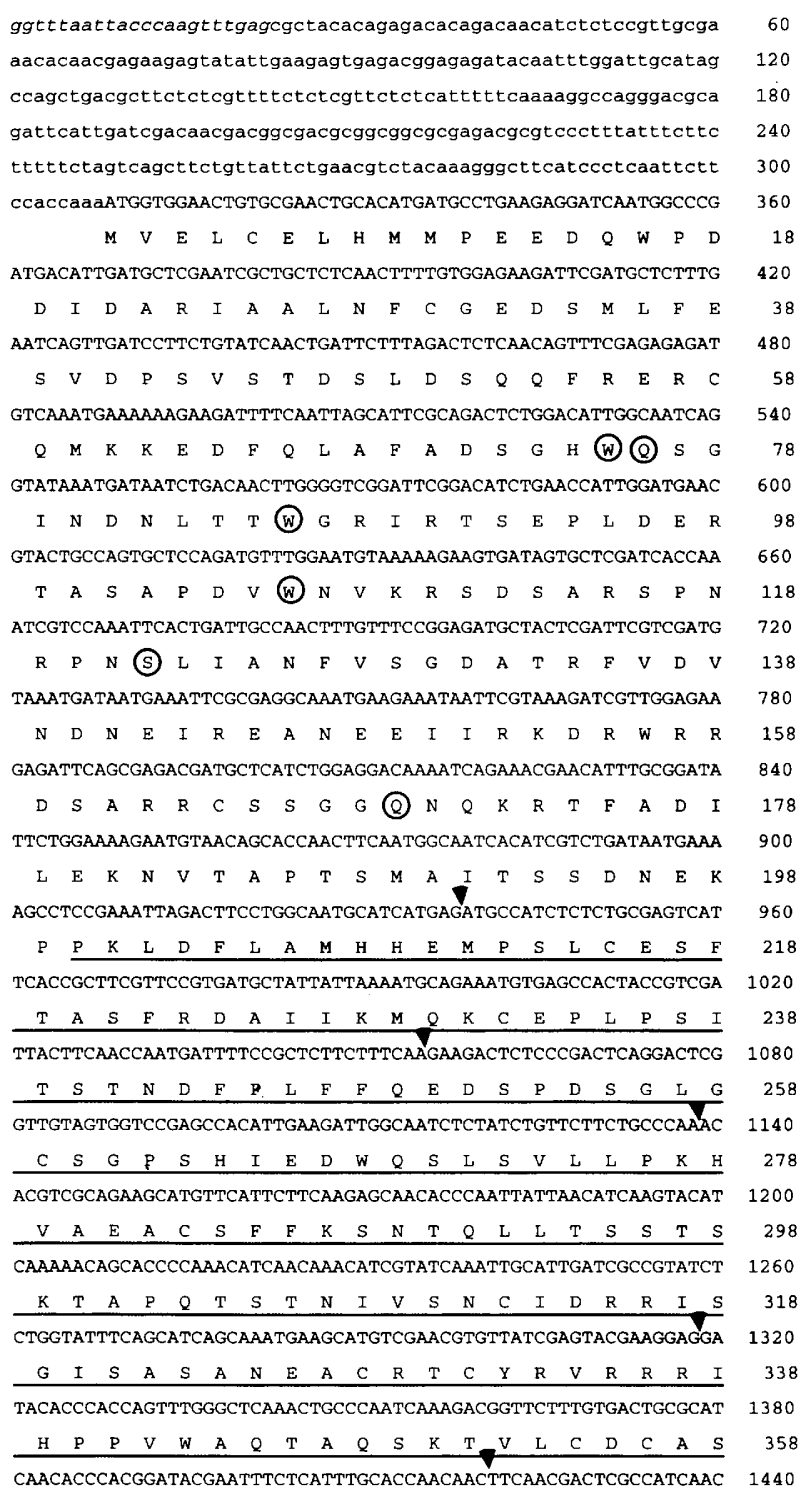

\begin{abstract}
$\begin{array}{llllllllllllllllllllll}T & P & T & D & T & N & F & S & F & A & P & T & T & S & T & T & R & H & Q & L & 378\end{array}$ TGCGCGCAAAAGAGCTCTCAATTGTCGGATTGCCGATTTATGCAGCAAAGCGGACACTCG 1500 $\begin{array}{lllllllllllllllllllllll}\mathrm{R} & \text { A } & \mathrm{K} & \mathrm{E} & \mathrm{L} & \mathrm{S} & \mathrm{I} & \mathrm{V} & \mathrm{G} & \mathrm{L} & \mathrm{P} & \mathrm{I} & \mathrm{Y} & \mathrm{A} & \mathrm{A} & \mathrm{K} & \mathrm{R} & \mathrm{T} & \mathrm{L} & \mathrm{V} & 398\end{array}$ TTGAGAATGTTGTTGAAGGCGTTGCTGCAATTTCAAGAGGGGATGGAAGTGATTTGCTTG 1560 $\begin{array}{lllllllllllllllllllll}\text { E } & \text { N } & \text { V } & \text { V } & \text { E } & \text { G } & \text { V } & \text { A } & \text { A } & \text { I } & \text { S } & \text { R } & \text { G } & \text { D } & \text { G } & \text { S } & \text { D } & \text { L } & \text { L } & \text { V } & 418\end{array}$ TCATCGCCATGAGATGCTTAATTGAAGATGGTCTTCAAGAAAATGTATCGGCATGGACAA 1620 $\begin{array}{llllllllllllllllllllll}\text { I } & A & M & R & C & \text { L } & \text { I } & \text { E } & \text { D } & G & \text { L } & \text { \& } & \text { E } & \text { N } & \text { V } & \text { S } & \text { A } & \text { W } & \text { T } & M & 438\end{array}$ TGATTCAGACGGTTACCTCAAAAGGCCCAGCTACAAAAGATGTTCATTCAATTGTAAAAC 1680 $\begin{array}{lllllllllllllllllllll}I & Q & T & V & T & S & K & G & P & A & T & K & D & V & H & S & I & V & K & Q & 458\end{array}$ AATTGGAAGAATGTTCAAAGACTGACAACGTCAAAGTTGAAATCTTCTTTGAGGAGCTTA 1740 $\begin{array}{lllllllllllllllllllll}L & E & E & C & S & K & T & D & N & V & K & V & E & I & F & F & E & E & L & I & 478\end{array}$ TCAGAGAAACTCATTGGACTGCTGGCTGTGCTATATTGTGTTGAAAGAGAaGgTGCTGA 1800 $\begin{array}{lllllllllllllllllllll}R & E & N & S & L & D & C & W & \text { L } & C & Y & I & V & L & K & E & K & V & L & K & 498\end{array}$ AAACATTGTATTCTGAAAATGCATTCCTTCTTTCTGCGAGTTCTGAATACAGAACTCTTC 1860 $\begin{array}{llllllllllllllllllllll}T & L & Y & S & E & N & A & F & L & L & S & A & S & S & E & Y & R & T & L & L & 518\end{array}$ TTTGGAGATGGTCGACAGTTTGTCTCTTTTGCCAGTGATCGAAGCTCGCAGTGATTCAG 1920

$\begin{array}{lllllllllllllllllllll}\text { W } & R & M & \text { V } & \text { D } & \text { S } & \text { L } & S & \text { L } & \text { L } & \text { P } & \text { V } & \text { I } & \text { E } & \text { A } & R & \text { S } & \text { D } & \text { S } & \text { V } & 538\end{array}$ TTCACCAACAGTTCAAATCAATGCAACAATGGGGCGGAGCATCCAGAATAGCTTCTGACT 1980 $\begin{array}{llllllllllllllllllllll}H & Q & Q & F & K & S & M & Q & Q & W & G & G & A & S & R & I & A & S & D & S & 558\end{array}$ CAAGAGTTCCAAAGAGTTCATCGTTCCCAGCAAGATTATCAACTGCTCCATCAAGAAGAT 2040 $\begin{array}{llllllllllllllllllllll}R & V & P & K & S & S & S & F & P & A & R & L & S & T & A & P & S & R & R & S & 578\end{array}$ CAAGGATACCATTGTCAACAAGTCGCATCAGTATCAGCTCAACAACTTCAACACCTCGAT 2100 $\begin{array}{lllllllllllllllllllll}R & I & P & L & S & T & S & R & I & S & I & S & S & T & T & S & T & P & R & S & 598\end{array}$ CAGCTCGATCACCTTCAACGACATCTCGTATTCGAGTTGCATCTATAATGGGTGACTTCA 2160 $\begin{array}{lllllllllllllllllllll}A & R & S & P & S & T & T & S & R & I & R & V & A & S & I & M & G & D & F & T & 618\end{array}$ CACTTGCCAATTTCTCCCTCTCAGACGGAGAAAAGTTAGTGTTCTATCAACTCGTGGAG 2220 $\begin{array}{llllllllllllllllllllll}\text { L } & A & N & F & S & L & S & D & G & E & K & V & S & V & L & S & T & R & G & G & 638\end{array}$ GACTTGCTCGATGTGTCCGTTTAACGACTTCTCATTCAAAAATCAACAATGGAGTTATTC 2280 $\begin{array}{lllllllllllllllllllll}\text { L } & A & R & C & \text { V } & R & \text { L } & \text { T } & \text { T } & \text { S } & \text { H } & \text { S } & \text { K } & \text { I } & \text { N } & \text { N } & G & \text { V } & \text { I } & P & 658\end{array}$ CGATTGAACATCTTCTTTTCCAGtgaacactctgtactttattttttettgaactttaa 2340 I $E$ H tttttttccgatgcttcatataattctagtcatgccacccaattcaaccgagtttgatcc 2400 cccatcccatgcattcatcgtttccctcaatgatactcatttcttttcatgttcaact 2460 gaattcatgaaaaatgtttgaaaactttcaaatatttttttgaatttaaaagtcattaga 2520 tagcctctctttccctccggtttcctccaattttgctccttctatcttcgtatagaaga 2580 aaattgctttatttccttccttttcagctaaaatcgaggcaactattggattctttgca 2640 gcttgccaaaacattattcaataacaaaaacgaaaatgtttatttgtattttggaataga 2700 gccaatcggatttgtattgtttttgaaataaacaataaataaaatgcatttaaaaaaa 2760
\end{abstract}

Figure 3. Nucleotide sequence of the unc-14 cDNA and the deduced amino acid sequence of UNC-14. SL1 spliced leader sequence at the $5^{\prime}$ end is represented in italics. The UNC-51 binding region is underlined. The amino acids mutated to nonsense codons in the unc-14 mutants are shown by circles. $(\boldsymbol{\nabla})$ The positions of the introns; $\left(^{*}\right)$ the termination codon. The presumed polyadenylation signal is indicated by double underlines.

in unc-14 and unc-51 mutants (McIntire et al. 1992), we analyzed the expression in these neurons of unc-14 or unc-51 promoter fusions with the green fluorescent protein (GFP) (Chalfie et al. 1994). Staining of DD/VD neurons with an anti-GABA antibody and the fluorescence of UNC-14::GFP or UNC-51::GFP showed that they were both expressed in these neurons (Fig. 6A-C,G-I). Staining with an anti-serotonin antibody revealed coexpression of unc-14::gfp and unc-51::gfp in serotonergic HSN neurons (Fig. 6D-F,J-L). Expression of unc-14::gfp was observed also in late embryos (data not shown), as was expression of unc-51::1acZ fusion (Ogura et al. 1994). Because unc-14::gfp expression and unc-51::gfp expression do not vary significantly with developmental stages, we suggest that both unc-14 and unc-51 genes are also expressed when these neurons extend axons.

\section{Regions of UNC-14 and UNC-51 for intermolecular interaction}

The recovery of unc-14 cDNAs and an UNC-51 carboxyterminal cDNA in the yeast two-hybrid screen using UNC-51 as a bait raised several questions. Does UNC-14 interact with protein kinase UNC-51 as a substrate or a regulator? Does the carboxy-terminal region of UNC-51 bind the kinase domain intramolecularly, or is it required for oligomerization? To answer these ques- 


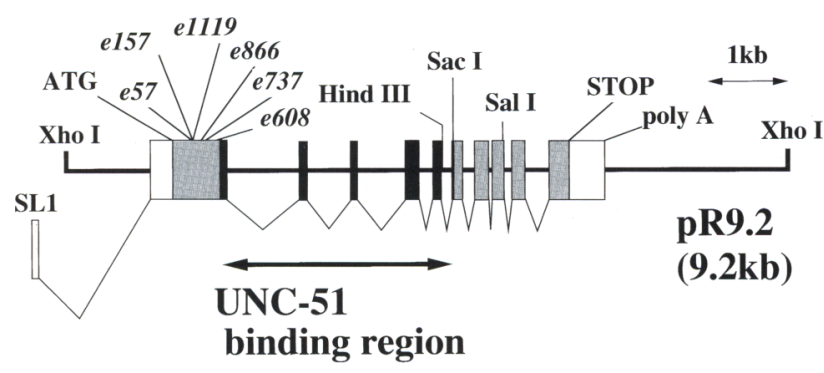

Figure 4. Genomic structure of the unc-14 gene. (ATG) A putative initiation methionine; (STOP) the stop codon; (Poly A) a putative polyadenylation signal. The mutation sites in the six unc-14 mutants are indicated by their allele names. Boxes represent exons. Solid boxes represent the UNC-51 binding domain; shaded boxes represent the other coding regions. SL1 shows the splice leader sequence. Although we had originally sequenced this region, it was later sequenced by the C. elegans genome project. K10D3.2 gene predicted by the Gene Finder corresponds to the UNC-14 coding region, but has an incorrect splicing pattern, in which exon 7 is linked to exon 10 .

tions, the interacting regions were analyzed by using the yeast two-hybrid system (Table 2). A central region of UNC-14 (amino acid residues 200-382) interacted with a carboxy-terminal region of UNC-51(455-856) downstream of the kinase domain. Also, this same carboxyterminal region of UNC-51 was able to self-associate (Table 2; Fig. 7). These results suggest that UNC-51 acts as an oligomer and that UNC-14 interacts with UNC-51 in the oligomerization domain outside of the kinase domain.

\section{Association of UNC-51 and UNC-14 in vitro}

To confirm the direct interaction between UNC-51 and UNC-14, interactions of recombinant proteins produced by Escherichia coli were analyzed. The carboxy-terminal region of UNC-51(455-856) and a mutant form (R841H) of the same UNC-51 region, corresponding to the $e 1120$ mutation (Ogura et al. 1994), were expressed as fusions with glutathione $S$-transferase (GST). The GST fusion proteins were immobilized on glutathione-Sepharose 4B beads. A fragment of UNC-14(1-382) including the amino terminus and the UNC-51 binding region was expressed as a fusion with maltose binding protein (MBP). The GST-UNC-51 fusion proteins immobilized on beads were mixed with an extract of $E$. coli that produced MBP-UNC-14(1-382). The interaction among these pro-

Table 1. Mutation sites of unc-14 alleles

\begin{tabular}{|c|c|c|c|}
\hline Alleles & & Autation site /codo & on) \\
\hline$e 57$ & $75 \mathrm{~W}$ & $($ TGG $) \rightarrow$ STOP & (TGA) \\
\hline e157 & $76 \mathbf{Q}$ & $|\underline{C A A}| \rightarrow$ STOP & (IIAA) \\
\hline e1119 & $86 \mathbf{W}$ & $(\overline{\mathrm{T}} \underline{\mathrm{G}} \mathrm{G}) \rightarrow \mathrm{STOP}$ & (T⿱一𫝀口AGG) \\
\hline$e 866$ & $106 \mathrm{~W}$ & $(\overline{\mathrm{TG}} \underline{\mathrm{G}}) \rightarrow \mathrm{STOP}$ & 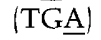 \\
\hline e737 & $122 \mathrm{~s}$ & $|\mathrm{TC} \overline{\mathrm{A}}| \rightarrow$ STOP & (TA-A) \\
\hline$e 608$ & $169 \mathbf{Q}$ & $(\underline{\mathrm{CA}} \overline{\mathrm{A}}) \rightarrow$ STOP & ( $\underline{\overline{T A}} \bar{A})$ \\
\hline
\end{tabular}
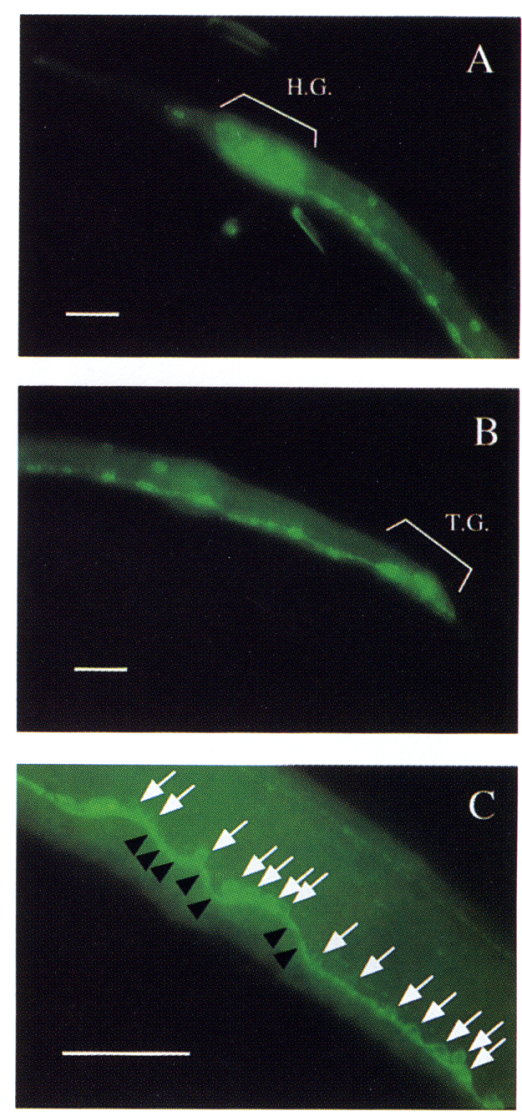

Figure 5. Expression patterns of an unc-14::1acZ fusion gene. The Sall fragment of pR9.2 shown in Fig. 4 was subcloned in lacZ expression vector pPD22.04. This unc-14::1acZ fusion gene is capable of rescuing an unc-14 mutant. The transgenic worms were fixed and stained with an anti-LacZ antibody. $|A| \mathrm{L} 2$ worm head region. (H.G.) head ganglia. $(B)$ The posterior part of the same worm. (T.G.) Tail ganglia. (C) A higher magnification picture of the middle-body region of an L2 worm. White arrows represent cell bodies of ventral neurons. Black arrowheads represent the ventral nerve cord. Bar, $50 \mu \mathrm{m}$.

teins was observed by Western blotting and an anti-MBP antiserum. The carboxy-terminal region of UNC51(455-856) and the 1-382 region of UNC-14 interacted directly, and the mutation in the carboxy-terminal region of UNC-51 reduced the binding dramatically (Fig. 8). Attempts in vitro to detect self-association of the UNC-51 carboxy-terminal region were not reproducibly successful. We presume that this result was either because the produced UNC-51 fusions had already self-associated or because the self-association was not strong enough to be detected reproducibly under the conditions used.

\section{Discussion}

\section{UNC-14 and UNC-51 can interact directly}

By positional cloning, we identified the unc-14 gene and showed that it encoded the cDNAs isolated in a two-hybrid screen with an UNC-51 bait (Figs. 1 and 2). 
Ogura et al.
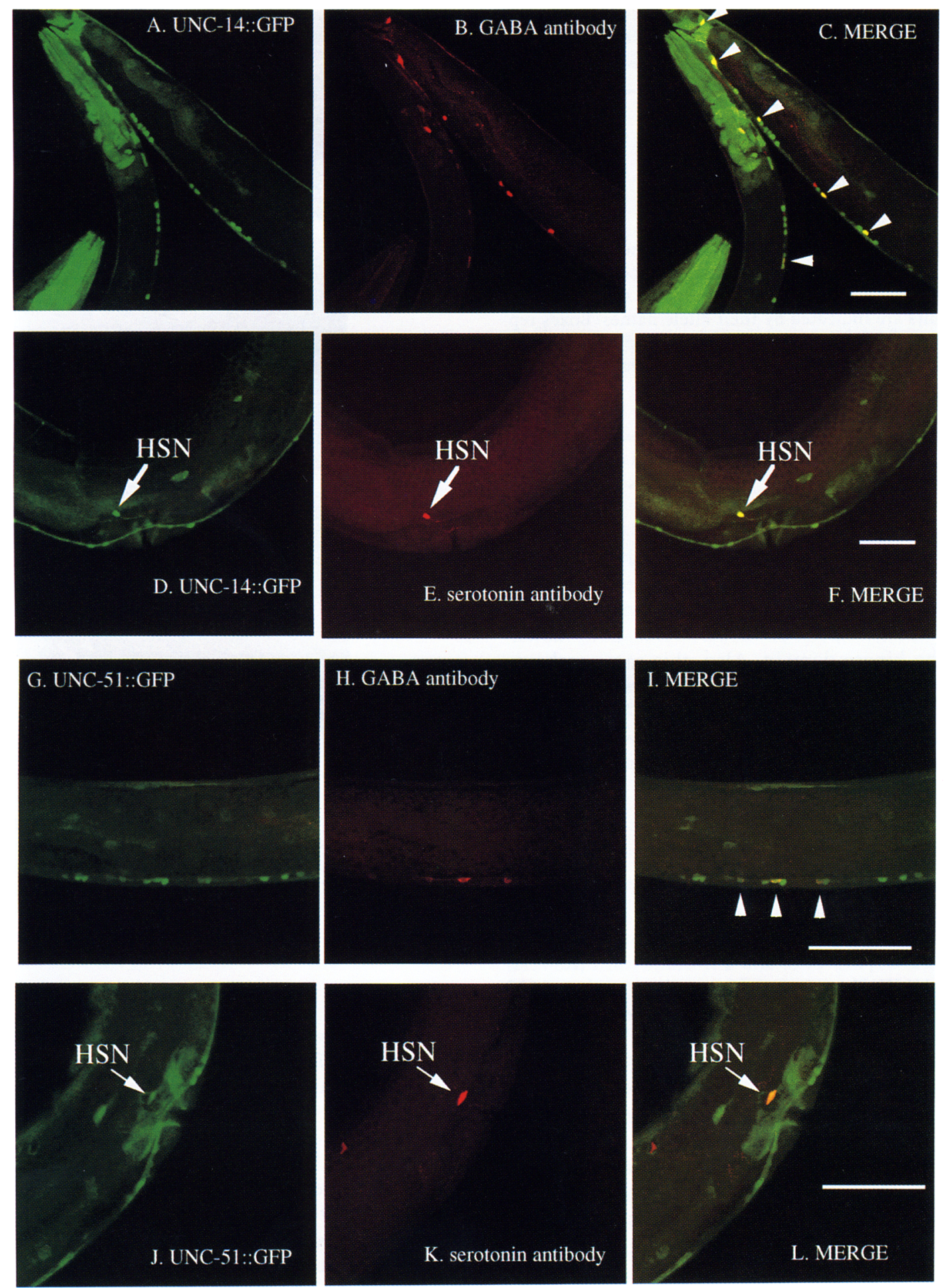

Figure 6. Expression of unc-14::gfp and unc-51::gfp fusion genes in DD/VD and HSN neurons. Green represents GFP fluorescence, and red (Texas Red) represents neurons stained with an anti-GABA antibody or HSN neurons stained with an anti-serotonin antibody. A Zeiss LSM410 confocal laser scanning microscope was used in these analyses. Bar, $50 \mu \mathrm{m}$. $(A-F)$ Transgenic animals that express an unc-14::gfp promoter fusion gene. $(A, D)$ unc-14::GFP (green). $(B, E)$ Staining with an antibody to GABA or serotonin (red). (C,F) Merge of $A$ and $B$ or $D$ and $E$. The yellow color indicated by the arrows represents coexpression. $(G-L)$ Transgenic animals that express an unc-51::gfp promoter fusion gene. $(G, J)$ unc-51::GFP (green). $(H, K)$ Staining with an antibody to GABA or serotonin (red). $(I, L)$ Merge of $G$ and $H$ or $I$ and $K$. Yellow color indicated by arrowheads represents coexpression. The total number of cell bodies stained by the GABA antibody, including those in other focal planes, in a whole animal is $\sim 20$. They include most of the 19 DD/VD neurons (McIntire et al. 1992), and most of them express unc-14::GFP and unc-51::GFP. 
Table 2. Interaction between UNC-51 and UNC-14, and UNC-51 self-interaction in the yeast two-hybrid system

\begin{tabular}{|c|c|c|c|c|c|}
\hline \multirow[b]{3}{*}{ Activation domain fusion } & \multicolumn{5}{|c|}{ Binding domain fusion } \\
\hline & \multirow{2}{*}{$\begin{array}{l}\text { UNC-14 } \\
(1-665)\end{array}$} & \multicolumn{3}{|c|}{ (UNC-51) } & \multirow[b]{2}{*}{ Snf1 } \\
\hline & & $(1-856)$ & $(455-856)$ & $1-2881$ & \\
\hline UNC-51 (1-856) & + & + & $-^{\star}$ & - & - \\
\hline UNC-51 $\{1-288\}$ & - & - & - & - & N.D. \\
\hline UNC-51 (289-856) & + & + & $-{ }^{\star \star}$ & N.D. & - \\
\hline UNC-51 (160-655) & - & - & - & N.D. & N.D. \\
\hline UNC-51 (656-856) & - & - & - & N.D. & N.D. \\
\hline UNC-51 (455-856) & + & + & + & - & - \\
\hline UNC-14 (1-665) & - & + & + & - & - \\
\hline UNC-14 (126-643) & - & + & + & N.D. & - \\
\hline UNC-14 (200-665) & N.D. & + & + & N.D. & - \\
\hline UNC-14 (1-382) & - & + & + & - & - \\
\hline UNC-14 (1-522) & - & + & + & - & - \\
\hline UNC-14 (200-382) & - & + & + & - & - \\
\hline UNC-14 (383-665) & N.D. & - & - & N.D. & N.D. \\
\hline SNF4 & - & - & - & N.D. & + \\
\hline
\end{tabular}

$\beta$-Galactosidase activities were determined by a filter assay (Durfee et al. 1993) in Y190 yeast strain containing the indicated plasmids. (+) A positive result in which at least several colonies changed to blue in $24 \mathrm{hr}_{;}(-)$A negative result in which no colony changed to blue in 24 hr. (N.D.) Not done. Contradictory results in the sense that the result of the reverse pair of fusions as to binding and activation domains was $+\left(^{*}\right)$ or that the expected result should be $+\left(^{\star *}\right)$. We believe that conformation or stability of the fusion protein may be responsible for these results.

The unc-14 gene encodes a novel protein (Fig. 3), whereas unc-51 encoded a putative neuronal protein kinase (Ogura et al. 1994). Bacterially expressed recombinant proteins revealed direct interactions between UNC-14 and UNC-51 (Fig. 8). An UNC-14::LacZ fusion protein was localized to neuronal axons and cell bodies (Fig. 5). Its expression pattern overlapped that of an UNC$51::$ LacZ fusion protein (Ogura et al. 1994). In particular, both unc-14 and unc-51 genes are expressed in DD/VD and HSN neurons (Fig. 6). Furthermore, unc-51 and unc14 mutants share similar defects in axonal outgrowth and abnormal axonal structures (see introductory section). Thus, we suggest that UNC-51 and UNC-14 interact in neurons, and this interaction is required for normal axonal elongation and/or guidance.

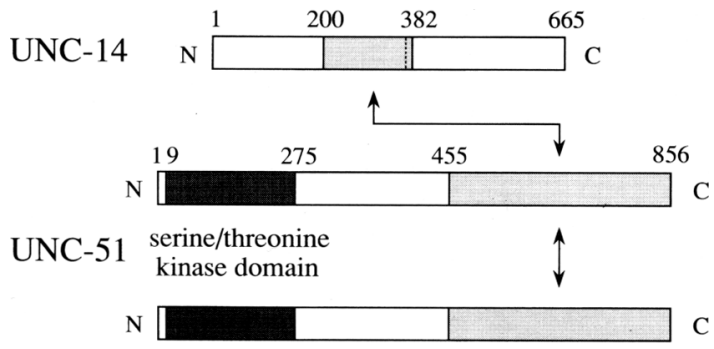

Figure 7. Schematic representations of the interaction between UNC-14 and UNC-51, and of the UNC-51 self-interaction. The region in UNC-14 between the dotted line (at position 370 ) and the carboxyl terminus is not essential for the rescue of unc-14 mutant phenotypes in germline transformation (see Results).
Interaction between UNC-14 and UNC-51 and oligomerization of UNC-51 are important for their function

We found that the carboxy-terminal region of UNC-51 could bind to a central region of UNC-14 (Table 2; Figs.

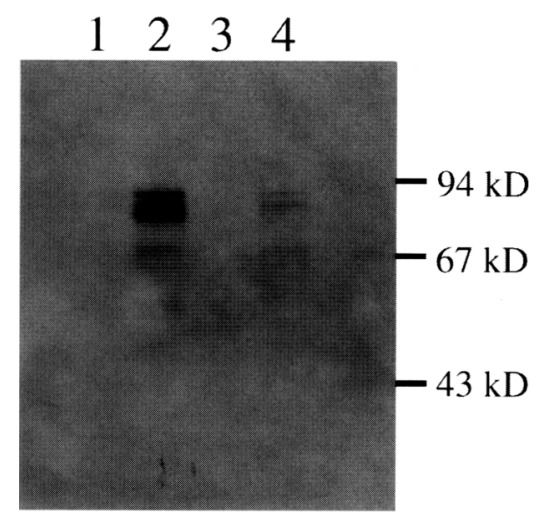

Figure 8. In vitro binding studies. GST, GST-UNC-51/455856) fusion, MBP, or MBP-UNC-14(1-382) fusion were expressed in E. coli. GST or a GST fusion was immobilized on beads and the beads were mixed with an extract including MBP or an MBP fusion. MBP or MBP fusion proteins bound to the beads were detected by Western blotting analysis using an antiMBP antiserum as described in the Materials and Methods. (Lane 1) GST and MBP-UNC-14; (lane 2) GST-UNC-51 and MBP-UNC-14; (lane 3) GST-UNC-51 and MBP; (lane 4) GSTM.UNC-51 and MBP-UNC-14. The predicted molecular weight of the MBP-UNC-14 is $87 \mathrm{kD}$, and the multiple bands shown in lanes 2 and 4 are probably attributable to protein degradation. 
7 and 8), and a mutation in the carboxy-terminal region of UNC-51 decreased the binding dramatically (Fig. 8). In addition, because each of the six unc-14 alleles analyzed in this study has a nonsense mutation near the amino terminus of UNC-14 (Figs. 3 and 4; Table 1), the UNC-51 binding domain should not be translated in these mutants. The carboxy-terminal region of UNC-51(455-856), which is necessary for UNC-14 binding, was shown previously to be important for the UNC-51 function by the severe phenotype of unc-51(e369) nonsense mutation at amino acid 553 within the carboxy-terminal region (Ogura et al. 1994). All these results suggest that the interaction between UNC-14 and UNC-51 is important for their respective functions. We have also shown that the carboxy-terminal region of UNC-51 self-associated in the yeast two-hybrid system (Table 2; Fig. 7). This suggests that oligomerization of UNC-51 kinase is also important for its function. Consistent with this, two groups reported recently that artificial oligomerization activates the serine/threonine kinase Raf-1 (Farrar et al. 1996; Luo et al. 1996).

\section{Functions of UNC-14 and UNC-51}

What is the function of UNC-14? UNC-14 is likely to be required for UNC-51 function, because UNC-14 binds to UNC-51 and because all of the unc-14 alleles are recessive nonsense mutations and therefore probably have lost the function. We propose the following three models consistent with this notion. In the first model, UNC-14 is a regulator, possibly an activator, of UNC-51. In this model, UNC-51 exists in an inactive (and possibly oligomerized) form, and binding of UNC-14 to the carboxyterminal region of UNC-51 activates the kinase activity as with the binding of Cdc42 to p21-(Cdc42/RAC) activated kinase (PAK) (Manser et al. 1994) or TAK1-binding protein 1 (Tab1) to transformation growth factor (TGF $\beta$ )activated kinase 1 (Tak1) (Shibuya et al. 1996), or stabilizes the active oligomer of UNC-51 (Fig. 9A). In the second model, UNC-14 recruits the UNC-51 to a certain intracellular region (Fig. 9B), like the function of Lin-7 in relation to Let-23 (Simske et al. 1996) or that of NMY-2 to PAR-1 (Guo and Kemphues 1996). For example, UNC51 may be brought from a cytoplasmic location to the axonal membrane by UNC-14, where it phosphorylates its substrate. This model is consistent with the finding that unc-14 and unc-51 mutants have a defect in axonal membrane structures (see Introduction). In the third model, UNC-14 may tether UNC-51 to another factor or substrate (Fig. 9C) as Ste5p functions in the regulation of Ste11, Ste7, and Fus3 (Choi et al. 1994). These models are not always mutually exclusive. In all of the above models, UNC-14 is not presumed to be a substrate of UNC51 kinase. Although UNC-14 could possibly be a substrate, we prefer the models in which it is not a substrate. Our view is based on the results that the interaction between the UNC-51 kinase domain and UNC-14 was not detected in the two-hybrid system. A substrate of UNC-51 has yet to be identified.

McIntire et al. (1992) showed that unc-14(e57) mutant had less severe defects compared with unc-51(e369), except for the circumferential elongation of HSN nerons. In addition, unc-14(e57) mutant worms are somewhat motile in contrast to unc-51(e369). unc-14(e57) is predicted to produce a protein of only 74 amino acids suggesting that this allele is null. unc-51(e369) nonsense mutation at position 553 (Ogura et al. 1994) results in the loss of most of the carboxy-terminal UNC-14 binding region. If the function of UNC-14 is absolutely required for UNC-51, the phenotypes of the null or severe mutants in these genes should be the same. The phenotypic difference between these mutants suggests that UNC-51 partially functions without UNC-14, or that another positive regulator of UNC-51 may exist.

The reporter constructs of unc-51 and unc-14 genes are strongly expressed also in adults in many neurons (Fig. 6; Ogura et al. 1994), long after the time when the axons affected in the mutants are extending. Therefore, it is possible that UNC-51 and UNC-14 are required not only
Figure 9. Models for the role of UNC-14 in the function of UNC-51. (A) UNC-14 is an activator of UNC-51. When UNC-14 binds to the UNC-51 oligomer, UNC-51 changes from an inactive form to an active form and phosphorylates a protein that regulates axonal elongation or path-finding. (B) UNC-14 is a recruiter of UNC-51. An UNC-51 oligomer is transported by UNC-14 to a certain site in neurons, where UNC-51 phosphorylates a protein required for axonal elongation or pathfinding. $(C)$ UNC-14 tethers UNC-51 to another protein $(\mathrm{Y})$.
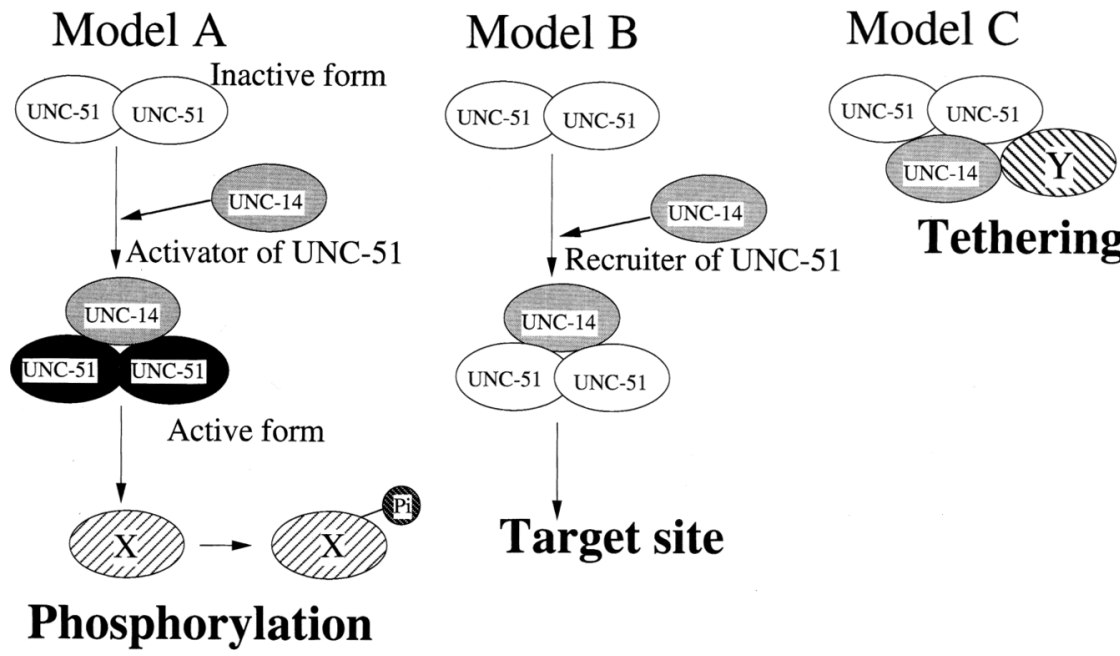

Tethering 
for axonal elongation and guidance but also either for maintenance or for an unknown neural function in the adult.

\section{Materials and methods}

\section{C. elegans strains}

Wild-type strain N2, CB369(e369) and CB57(e57) were provided by Caenorhabditis Genetics Center. unc-14 mutant strains CB157(e157), CB608(e608), CB737(e737), CB866(e866), and CB1119(e1119) were provided by J. Hodgkin (Medical Research Council, UK). Iin-15(n765) was provided by P. Sengupta and C. Bargmann (University of California, San Francisco). Worms were grown on the NGM agar plates with OP50 strain of $E$. coli at $20^{\circ} \mathrm{C}$ (Brenner 1974; Wood 1988) except for lin-15(n765), which was grown at $15^{\circ} \mathrm{C}$.

\section{Molecular manipulations}

Molecular manipulations of DNA or RNA were performed essentially according to Sambrook et al. (1989). The mutation sites were located by sequencing reverse transcription-PCR products of the total RNA of the mutants. The accession number in DDBJ/EMBL/GenBank for the unc-14 cDNA sequence reported in this paper is $\mathrm{AB} 000913$.

\section{Yeast two-hybrid screening and analysis}

The C. elegans cDNA library in $\lambda$ ACT vector for two-hybrid screen in this study was kindly provided by R. Barstead /Oklahoma Medical Research Foundation, Oklahoma City). Yeast strain Y190 was used as the host. Vectors used in this study were pAS2 (for fusion with GAL4 DNA-binding domain) and pACT or pACT2 (for fusion with GAL4 transcriptional activator domain). For library screening, an unc-51 cDNA fragment corresponding to the full-length UNC-51 (amino acids 1-856) was used. Library screening and $\beta$-galactosidase filter assays were performed as described in Durfee et al. (1993).

\section{In vitro binding}

The carboxy-terminal region of wild-type UNC-51 (amino acids 455-856) and M.UNC-51 (amino acids 455-856) carrying R841H mutation corresponding to 1120 were expressed as GST fusion proteins by using pGEX-KG vector (Guan and Dixon 1991). pMALc2 (New England Biolabs) was used for expression of MBP-UNC-14 (amino-terminal region, amino acids 1-382) fusion proteins. E. coli strain BL21(DE3) harboring pT-Trx was used for producing soluble fusion proteins (Yasukawa et al. 1995 ). Fusion proteins were induced by $1 \mathrm{mM}$ IPTG at $37^{\circ} \mathrm{C}$ for $3 \mathrm{hr}$. The $E$. coli cells that produced recombinant proteins were sonicated on ice in $1 \times \mathrm{PBS}\left(140 \mathrm{mM} \mathrm{NaCl}, 8.1 \mathrm{mM} \mathrm{Na} 2 \mathrm{HPO}_{4}, 2.7\right.$ $\mathrm{mM} \mathrm{KCl}, 1.5 \mathrm{mM} \mathrm{KH}_{2} \mathrm{PO}_{4}$ ) containing $0.1 \%$ Triton X-100 and 10 mM $\beta$-mercaptoethanol. About 2- $\mu$ g of GST, GST-UNC-51, or GST-M.UNC-51 was immobilized on $50 \mu \mathrm{l}$ of glutathioneSepharose 4B beads (Pharmacia Biotech) and purified. The beads were mixed with an extract of $E$. coli that produced MBP $(\sim 4 \mu \mathrm{g})$ or MBP-UNC-14 $(\sim 1 \mu \mathrm{g})$ in $1 \times$ PBS containing $0.1 \%$ Triton $\mathrm{X}-100$ and $10 \mathrm{~mm} \beta$-mercaptoethanol. The beads were washed several times in the buffer for sonication. Each sample was fractionated by $8 \%$ SDS-PAGE and analyzed by ECL Western blotting (Amersham). We used an anti-MBP antiserum (New England Biolabs) for the primary antibody, and HRP conjugated anti-rabbit IgG (Cappel) for the secondary antibody.
Rescue of an unc-14 mutation

Following the method of Mello et al. (1991), cosmid or plasmid DNA was injected into the syncytial gonads of adult hermaphrodites of an unc-14 mutant at a total concentration of $100 \mathrm{ng} / \mu \mathrm{l}$ or $1 \mathrm{ng} / \mathrm{\mu l}$ (Barnes et al. 1996). pPD10.46 (Fire et al. 1991) or pRF4 carrying rol- $6^{d}$ gene (Kramer et al. 1990) was used for the cotransformation marker.

\section{Construction and expression of lacZ fusion or gfp fusion constructs}

The 5.4-kb SalI fragment of the unc-14 gene was subcloned into the Sall site of the lacZ expression vector pPD22.04 (Fire et al. 1990). This plasmid was named p04SS. For transformation, a 1:1:8 mixture of p04SS, pR9.2 (intact unc-14 gene), and pBluescript SK+ (Stratagene, for dilution) at a total concentration of $100 \mathrm{ng} / \mathrm{\mu l}$ was injected into unc-14(e57) mutant. Non-Unu transgenic worms were selected. Although this unc-14::1acZ fusion gene had a nuclear localization signal, no nuclear staining was observed. This unc-14:: lacZ fusion gene is capable of rescuing unc-14(e57) mutant, when injected together with pPD10.46.

For coexpression analysis, the putative promoter region of the unc-51 gene (4-kb EcoRI-BstXI fragment; Ogura et al. 1994) was subcloned into the XmaI site of the $g f p$ expression vector pGFPTT (kindly provided by Y. Jin and H.R. Horvitz, Massachusetts Institute of Technology, Cambridge). This plasmid was named pTTu51P. The putative promoter region $(1.4 \mathrm{~kb})$ of the unc-14 gene was amplified by PCR and subcloned into the XmaI site of pGFP-TT (pTTu14P). For transformation, a 1:1 mixture of pTTu51P or pTTu14P and pIM23 carrying lin-15(+) gene (Huang et al. 1994) was injected into lin-15(n765) hermaphrodites at a total concentration of $100 \mathrm{ng} / \mu \mathrm{l}$. Non-Lin worms with a normal vulva grown at $25^{\circ} \mathrm{C}$ were selected as transgenic animals.

\section{Indirect immunofluorescence staining with an antibody}

Staining with an anti-LacZ antibody (Cappel) was performed essentially according to the protocol described by Finney and Ruvkun (1990) except for fixation (2\% paraformaldehyde and 1× MRWB for $45 \mathrm{~min}$ at $4^{\circ} \mathrm{C}$ ). The specimens were observed in a Zeiss Axioplan fluorescence microscope. Simultaneous visualization of GFP and GABA or serotonin by an anti-GABA antibody (Sigma) or an anti-serotonin antibody (purchased from $\mathrm{H}$. Steinbusch, University of Limburg, Maastricht, Germany/ was performed by the same protocol as for anti-serotonin staining (Link et al. 1992; McIntire et al. 1992). The specimens were observed using a confocal laser scanning microscope (Zeiss, LSM410).

\section{Acknowledgments}

We thank N. Hayashi for a two-hybrid vector and technical advice, R. Barstead for the cDNA library and two hybrid vectors, S.J. Elledge for permission to use the two-hybrid system, S. Ishii for an E. coli strain, A. Coulson for cosmid clones, Y. Kohara for unpublished cDNA information, Y. Jin and H.R. Horvitz for pGFP-TT vector, G. Garriga for advice on immunostaining, A. Fire for pPD22.04 and pPD10.46 vectors, J.M. Kramer for pRF4, J. Hodgkin for mutant worms, P. Sengupta and C. Bargmann for the gift of pJM23 and lin-15(n765), K. Saigo for anti-LacZ antibody, I. Mori and M. Koga for advice and discussion, A. Vouloumanos for some of the microinjections, I. Okano and $\mathrm{K}$. Mi- 
zuno for technical advice on protein expression, C.D. Link for advice on worm staining, M. Ohara for language assistance, and N. Furuno, T. Tani, S. Urushiyama, A.K. Azad, and other members of our laboratories for suggestions and discussions. Positional cloning of unc-14 was begun in the laboratory of G. Ruvkun. Some nematode strains used in this study were provided by the Caenorhabditis Genetics Center, which is funded by the National Institutes of Health, National Center for Research Resources. This research was supported by grants from the Ministry of Education, Science, Sports and Culture of Japan, and a grant from the Science and Technology Agency of Japan (to Y.O.) and a grant from the Medical Research Council of Canada (to S.H.).

The publication costs of this article were defrayed in part by payment of page charges. This article must therefore be hereby marked "advertisement" in accordance with 18 USC section 1734 solely to indicate this fact.

\section{References}

Bargmann, C.I. 1993. Genetic and cellular analysis of behavior in C. elegans. Annu. Rev. Neurosci. 16: 47-71.

Barnes, T.M., Y. Jin, H.R. Horvitz, G. Ruvkun, and S. Hekimi. 1996. The Caenorhabditis elegans behavioral gene unc-24 encodes a novel bipartite protein similar to both erythrocyte band 7.2 (stomatin) and nonspecific lipid transfer protein. $J$. Neurochem. 67: 46-57.

Basson, M. and H.R. Horvitz. 1996. The Caenorhabditis elegans gene sem-4 controls neuronal and mesodermal cell development and encodes a zinc finger protein. Genes \& Dev. 10: 1953-1965.

Brenner, S. 1974. The genetics of Caenorhabditis elegans. Genetics 77: 71-94.

Chalfie, M., Y. Tu, G. Euskirchen, W.W. Ward, and D.C. Prasher. 1994. Green fluorescent protein as a marker for gene expression. Science 263: 802-805.

Chan, S.S.-Y., H. Zheng, M.-W. Su, R. Wilk, M.T. Killeen, E.M. Hedgecock, and J.G. Culotti. 1996. UNC-40, a C. elegans homolog of DCC (Deleted in Colorectal Cancer), is required in motile cells responding to UNC-6 netrin cues. Cell 87: 187-195.

Chien, C.T., P.L. Bartel, R. Sternglanz, and S. Fields. 1991. The two-hybrid system: A method to identify and clone genes for proteins that interact with a protein of interest. Proc. Natl. Acad. Sci. 88: 9578-9582.

Choi, K., B. Satterberg, D.M. Lyons, and E.A. Elion. 1994. Ste5 tethers multiple protein kinases in the MAP kinase cascade required for mating in $S$. cerevisiae. Cell 78: 499-512.

Chuong, C.-M., T.-X. Jiang, E. Yin, and R.B. Widelitz. 1994. cDCC /chicken homologue to a gene deleted in colorectal carcinoma) is an epithelial adhesion molecule expressed in basal cells and involved in epithelial-mesenchymal interaction. Dev. Biol. 164: 383-397.

Colamarino, S.A. and M. Tessier-Lavigne. 1995. The axonal chemoattractant netrin- 1 is also a chemorepellent for trochlear motor axons. Cell 81: 621-629.

Desai, C., G. Garriga, S.L. McIntire, and H.R. Horvitz. 1988. A genetic pathway for the development of the Caenorhabditis elegans HSN motor neurons. Nature 336: 638-646.

Dibb, N.J., I.N. Maruyama, M. Krause, and J. Karn. 1989. Sequence analysis of the complete Caenorhabditis elegans myosin heavy chain gene family. J. Mol. Biol. 205: 603-613.

Durfee, T., K. Becherer, P.-L. Chen, S.-H. Yeh, Y. Yang, A.E. Kilburn, W.-H. Lee, and S.J. Elledge. 1993. The retinoblastoma protein associates with the protein phosphatase type 1 catalytic subunit. Genes \& Dev. 7: 555-569.
Farrar, M.A., J. Alberola-lla, and R.M. Perlmutter. 1996. Activation of the Raf-1 kinase cascade by coumermycin-induced dimerization. Nature 383: 178-181.

Fields, S. and O. Song. 1989. A novel genetic system to detect protein-protein interactions. Nature 340: 245-246.

Finney, M. and G. Ruvkun. 1990. The unc-86 gene product couples cell lineage and cell identity in C. elegans. Cell 63: 895-905.

Fire, A., S.W. Harrison, and D. Dixon. 1990. A modular set of lacZ fusion vectors for studying gene expression in Caenorhabditis elegans. Gene 93: 189-198.

Fire, A., D. Albertson, S.W. Harrison, and D.G. Moerman. 1991. Production of antisense RNA leads to effective and specific inhibition of gene expression in C. elegans muscle. Development 113: 503-514.

Goshima, Y., F. Nakamura, P. Strittmatter, and S.M. Strittmatter. 1995. Collapsin-induced growth cone collapse mediated by an intracellular protein related to UNC-33. Nature 376: 509-514.

Guan, K. and J.E. Dixon. 1991. Eukaryotic proteins expressed in Escherichia coli: An improved thrombin cleavage and purification procedure of fusion proteins with glutathione S-transferase. Anal. Biochem. 192: 262-267.

Guo, S. and K.J. Kemphues. 1996. A non-muscle myosin required for embryonic polarity in Caenorhabditis elegans. Nature 382: 455-458.

Hedgecock, E.M., J.G. Culotti, J.N. Thomson, and L.A. Perkins. 1985. Axonal guidance mutants of Caenorhabditis elegans identified by filling sensory neurons with fluorescein dyes. Dev. Biol. 111: 158-170.

Hedgecock, E.M., J.G. Culotti, D.H. Hall, and B.D. Stern. 1987. Genetics of cell and axon migrations in Caenorhabditis e1egans. Development 100: 365-382.

Hedgecock, E.M., J.G. Culotti, and D.H. Hall. 1990. The unc-5, unc-6, and unc-40 genes guide circumferential migrations of pioneer axons and mesodermal cells on the epidermis in $C$. elegans. Neuron 2: 61-85.

Hill, K.K., V. Bedian, J.-L. Juang, and F.M. Hoffmann. 1995. Genetic interactions between the Drosophila Abelson (Abl) tyrosine kinase and failed axon connections (fax), a novel protein in axon bundles. Genetics 141: 595-606.

Huang, L.S., P. Tzou, and P.W. Sternberg. 1994. The lin-15 locus encodes two negative regulators of Caenorhabditis elegans vulval development. Mol. Biol. Cell 5: 395-412.

Huang, X.-Y. and D. Hirsh. 1989. A second trans-spliced RNA leader sequence in the nematode Caenorhabditis elegans. Proc. Nat1. Acad. Sci. 86: 8640-8644.

Ishii, N., W.G. Wadsworth, B.D. Stern, J.G. Culotti, and E.M. Hedgecock. 1992. UNC-6, a laminin-related protein, guides cell and pioneer axon migrations in C. elegans. Neuron 9: 873-881.

Keino-Masu, K., M. Masu, L. Hinck, E.D. Leonardo, S.S.-Y. Chan, J.G. Culotti, and M. Tessier-Lavigne. 1996. Deleted in Colorectal Cancer (DCC) encodes a netrin receptor. Cell 87: 175-185.

Kim, Y.-T. and C.-F. Wu. 1987. Reversible blockage of neurite development and growth cone formation in neuronal cultures of a temperature-sensitive mutant of Drosophila. I. Neurosci. 7: 3245-3255.

Koenig, J.H., K. Saito, and K. Ikeda. 1983. Reversible control of synaptic transmission in a single gene mutant of Drosophila melanogaster. J. Cell Biol. 96: 1517-1522.

Kosaka, T. and K. Ikeda. 1983. Reversible blockage of membrane retrieval and endocytosis in the garland cell of the temperature-sensitive mutant of Drosophila melanogaster, shibi$r e^{t s 1}$. J. Cell Biol. 97: 499-507. 
Kramer, J.M., R.P. French, E. Park, and J.J. Johnson. 1990. The Caenorhabditis elegans rol-6 gene, which interacts with the sqt-1 collagen gene to determine organismal morphology, encodes a collagen. Mol. Cell. Biol. 10: 2081-2089.

Leung-Hagesteijn, C., A.M. Spence, B.D. Stern, Y. Zhou, M.-W. Su, E.M. Hedgecock, and J.G. Culotti. 1992. UNC-5, a transmembrane protein with immunoglobulin and thrombospondin type 1 domain, guides cell and pioneer axon migrations in C. elegans. Cell 71: 289-299.

Li, W., R.K. Herman, and J.E. Shaw. 1992. Analysis of the Caenorhabditis elegans axonal guidance and outgrowth gene unc-33. Genetics 132: 675-689.

Link, C.D., M.A. Silverman, M. Breen, K.E. Watt, and S.A. Dames. 1992. Characterization of Caenorhabditis elegans lectin-binding mutants. Genetics 131: 867-881.

Luo, Z., G. Tzivion, P.J. Belshaw, D. Vavvas, M. Marshall, and J. Avruch. 1996. Oligomerization activates C-RAF-1 through a Ras-dependent mechanism. Nature 383: 181-185.

Manser, E., T. Leung, H. Salihuddin, Z. Zhao, and L. Lim. 1994. A brain serine/threonine protein kinase activated by $\mathrm{Cdc} 42$ and Racl. Nature 367: 40-46.

McIntire, S.L., G. Garriga, J. White, D. Jacobson, and H.R. Horvitz. 1992. Genes necessary for directed axonal elongation or fasciculation in C. elegans. Neuron 8: 307-322.

Mello, C.C., J.M. Kramer, D. Stinchcomb, and V. Ambros. 1991. Efficient gene transfer in C. elegans: Extrachromosomal maintenance and integration of transforming sequences. EMBO J. 10: 3959-3970.

Ogura, K., C. Wicky, L. Magnenat, H. Tobler, I. Mori, F. Müller, and Y. Ohshima. 1994. Caenorhabditis elegans UNC-51 gene required for axonal elongation encodes a novel serine/ threonine kinase. Genes \& Dev. 8: 2389-2400.

Otsuka, A.J., R. Franco, B. Yang, K.H. Shim, L.Z. Tang, Y.Y. Zhang, P. Boontrakulpoontawee, A. Jeyaprakash, E. Hedgecock, and V.I. Wheaton. 1995. An ankyrin-related gene (unc44) is necessary for proper axonal guidance in Caenorhabditis elegans. I. Cell. Biol. 129: 1081-1092.

Pierceall, W.E., M.A. Reale, A.F. Candia, C.V. Wright, K.R. Cho, and E.R. Fearon. 1994. Expression of a homologue of the deleted in colorectal cancer (DCC) gene in the nervous system of developing Xenopus embryos. Dev. Biol. 166: 654665.

Sambrook, J., E.F. Fritsch, and T. Maniatis. 1989. Molecular cloning: A laboratory manual. Cold Spring Harbor Laboratory, Cold Spring Harbor, NY.

Serafini, T., T.E. Kennedy, M.J. Galko, C. Mirzayan, T.M. Jessell, and M. Tessier-Lavigne. 1994. The netrins define a family of axon outgrowth-promoting proteins homologous to $C$. elegans UNC-6. Cell 78: 409-424.

Shibuya, H., K. Yamaguchi, K. Shirakabe, A. Tonegawa, Y. Gotoh, N. Ueno, K. Irie, E. Nishida, and K. Matsumoto. 1996. TAB1: An activator of the TAK1 MAPKKK in TGF- $\beta$ signal transduction. Science 272: 1179-1182.

Siddiqui, S.S. 1990. Mutations affecting axonal growth and guidance of motor neurons and mechanosensory neurons in the nematode Caenorhabditis elegans. Neurosci. Res. Suppl. 13: S171-S190.

Simske, J.S., S.M. Kaech, S.A. Harp, and S.K. Kim. 1996. LET-23 receptor localization by the cell junction protein LIN-7 during C. elegans vulval induction. Cell 85: 195-204.

Starich, T.A., R.Y.N. Lee, C. Panzarella, L. Avery, and J.E. Shaw. 1996. eat-5 and unc-7 represent a multigene family in Caenorhabditis elegans involved in cell-cell coupling. $J$. Cell. Biol. 134: $537-548$.

Wadsworth, W.G., H. Bhatt, and E.M. Hedgecock. 1996. Neuroglia and pioneer neurons express UNC-6 to provide global and local netrin cues for guiding migrations in C. elegans. Neuron 16: 35-46.

Wood, W.B. 1988. The nematode Caenorhabditis elegans. Cold Spring Harbor Laboratory, Cold Spring Harbor, NY.

Yasukawa, T., C. Kanei-Ishii, T. Maekawa, J. Fujimoto, T. Yamamoto, and S. Ishii. 1995. Increase of solubility of foreign proteins in Escherichia coli by co-expression of the bacterial thioredoxin. J. Biol. Chem. 270: 25328-25331. 


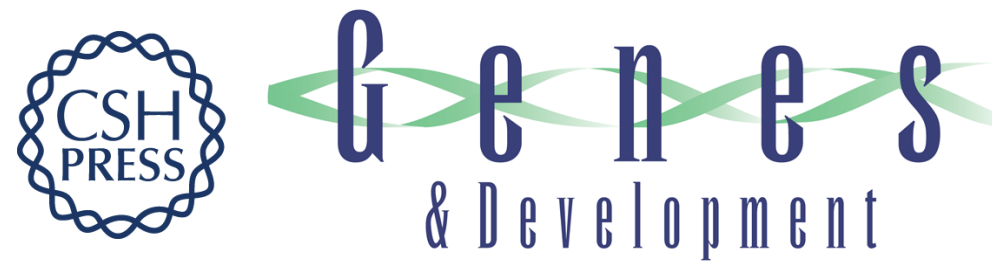

\section{The UNC-14 protein required for axonal elongation and guidance in Caenorhabditis elegans interacts with the serine/threonine kinase UNC-51.}

K Ogura, M Shirakawa, T M Barnes, et al.

Genes Dev. 1997, 11:

Access the most recent version at doi:10.1101/gad.11.14.1801

References This article cites 50 articles, 21 of which can be accessed free at:

http://genesdev.cshlp.org/content/11/14/1801.full.html\#ref-list-1

License

Email Alerting Receive free email alerts when new articles cite this article - sign up in the box at the top Service right corner of the article or click here.

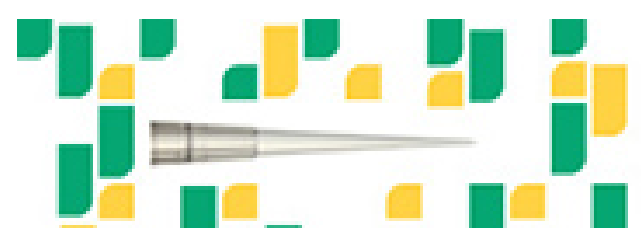

Focused on your science. 